\title{
Intestinal Perforation due to Deep Infiltrating Endometriosis during Pregnancy: Case Report
}

\section{Rotura intestinal durante a gravidez devido a endometriose profunda infiltrativa: relato de caso}

\author{
Márcia Mendonça Carneiro ${ }^{1}$ Luciana Maria Pyramo Costa ${ }^{1}$ Maria Das Graças Torres ${ }^{1}$ \\ Patrícia Salomé Gouvea ${ }^{1}$ Ivete de Ávila ${ }^{1}$ \\ ${ }^{1}$ Department of Obstetrics and Gynecology, Universidade, Federal de \\ Minas Gerais, Belo Horizonte, Minas Gerais, Brazil \\ Rev Bras Ginecol Obstet 2018;40:235-238. \\ Address for correspondence Márcia Mendonça Carneiro, MD, PhD, \\ Universidade Federal de Minas Gerais, Rua Antonio Torres 186, \\ Belo Horizonte, MG 31030-130, Brazil \\ (e-mail: marciamc.ufmg@gmail.com).
}

\begin{abstract}
Keywords

- deep infiltrating endometriosis

- intestinal endometriosis

- intestinal rupture

- pregnancy complications

Resumo

We report the case of a 33 year-old woman who complained of severe dysmenorrhea since menarche. From 2003 to 2009, she underwent 4 laparoscopies for the treatment of pain associated with endometriosis. After all four interventions, the pain recurred despite the use of gonadotropin-releasing hormone $(\mathrm{GnRH})$ analogues and the insertion of a levonorgestrel intrauterine system (LNG-IUS). Finally, a colonoscopy performed in 2010 revealed rectosigmoid stenosis probably due to extrinsic compression. The patient was advised to get pregnant before treating the intestinal lesion. Spontaneous pregnancy occurred soon after LNG-IUS removal in 2011. In the 33rd week of pregnancy, the patient started to feel severe abdominal pain. No fever or sings of pelviperitonitis were present, but as the pain worsened, a cesarean section was performed, with the delivery of a premature healthy male, and an intestinal rupture was identified. Severe peritoneal infection and sepsis ensued. A colostomy was performed, and the patient recovered after eight days in intensive care. Three months later, the colostomy was closed, and a new LNG-IUS was inserted. The patient then came to be treated by our multidisciplinary endometriosis team. The diagnostic evaluation revealed the presence of intestinal lesions with extrinsic compression of the rectum. She then underwent a laparoscopic excision of the endometriotic lesions, including an ovarian endometrioma, adhesiolysis and segmental colectomy in 2014. She is now fully recovered and planning a new pregnancy. A transvaginal ultrasound (TVUS) performed six months after surgery showed signs of pelvic adhesions, but no endometriotic lesions.

Relatamos o caso de uma mulher de 33 anos que apresentava de dismenorreia grave desde a menarca. Entre 2003 e 2009, a paciente foi submetida a quatro laparoscopias para o tratamento de dor associada à endometriose. A dor persistiu apos as 4 cirurgias apesar do uso de análogos do hormônio de liberação de gonadotropina (GnRH) e da inserção de um sistema intrauterino de levonorgestrel (SIU-LNG). Finalmente, uma
\end{abstract}

received

September 17, 2017

accepted

December 20, 2017
DOI https://doi.org/

10.1055/s-0038-1624579. ISSN 0100-7203.
Copyright $\odot 2018$ by Thieme Revinter Publicações Ltda, Rio de Janeiro, Brazil

License terms

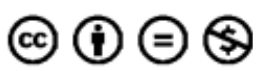




\begin{tabular}{|c|c|}
\hline $\begin{array}{l}\text { Palavras-Chave } \\
\text { - endometriose } \\
\text { infiltrativa } \\
\text { profunda } \\
\text { - endometriose } \\
\text { intestinal } \\
\text { - rotura intestinal } \\
\text { - complicações na } \\
\text { gravidez }\end{array}$ & $\begin{array}{l}\text { colonoscopia realizada em } 2010 \text { revelou estenose rectosigmoide, provavelmente } \\
\text { devido à compressão extrínseca. A paciente foi aconselhada a engravidar antes de } \\
\text { tratar a lesão intestinal. A gravidez espontânea ocorreu logo após a remoção de LNG- } \\
\text { IUS em } 2011 \text {. Na } 33^{a} \text { semana de gestação, a paciente começou a sentir dor abdominal } \\
\text { intensa, sem febre ou sinais de peritonite. Como a dor piorou consideravelmente, a } \\
\text { paciente foi submetida à cesariana com nascimento prematuro de um menino } \\
\text { saudável. Durante a cesárea foi identificado rotura intestinal com peritonite grave e } \\
\text { sepse. Uma colostomia foi realizada, e a paciente admitida no centro de terapia } \\
\text { intensiva por } 8 \text { dais. A colostomia foi fechada e um novo SIU-LNG inserido. A paciente } \\
\text { passou a ser tratada pela nossa equipe multidisciplinar de endometriose. A avaliação } \\
\text { diagnóstica revelou a presença de lesões intestinais com compressão extrínseca do } \\
\text { reto. Foi então submetida a uma excisão laparoscópica das lesões endometrióticas, } \\
\text { incluindo um endometrioma ovariano, adesiólise e colectomia segmentar em 2014. Ela } \\
\text { está agora totalmente recuperada e planeja nova gravidez. Uma ultrassonografia } \\
\text { transvaginal (TVUS) realizada seis meses após a cirurgia revelou sinais de aderências } \\
\text { pélvicas sem lesões de endometriose. }\end{array}$ \\
\hline
\end{tabular}

\section{Introduction}

Endometriosis is a progressive and benign estrogen-dependent disease defined by the presence of endometrial tissue (glands and stroma) outside the uterine cavity. Deep infiltrating endometriosis (DIE) is considered a specific entity, which has been arbitrarily defined in histological terms as endometriotic lesions extending more than $5 \mathrm{~mm}$ underneath the peritoneum, and it is responsible for painful symptoms, with some women experiencing severe symptoms, while others remain asymptomatic. ${ }^{1}$ Due to the variable clinical presentation, the lack of pathognomonic symptoms, and the fact that no useful noninvasive clinical tests to diagnose the symptomatic disease are available, a delay in the diagnosis that averages from 5 to 11 years is observed. ${ }^{1,2}$

Deep infiltrating endometriosis is found in $20 \%$ of women with endometriosis. Bowel involvement is diagnosed in $5 \%$ to $12 \%$ of patients with endometriosis, with most lesions (90\%) located in the colorectum. The role of colorectal endometriosis in women with infertility remains to be established. ${ }^{1,3}$ Unfortunately, in most published studies, fertility and pregnancy data are underreported or not fully considered. ${ }^{4}$ Intestinal DIE is a severe disease that may affect young women desiring pregnancy. Digestive symptoms may be found in association with deep dyspareunia, infertility, and impaired quality of life. In order to determine the best approach to bowel endometriosis, several factors such as clinical symptoms, extent of the disease and imaging evaluation results should be taken into consideration. 2,4,5

\section{Case Summary}

We report the case of a 33 year-old woman who complained of severe dysmenorrhea since menarche. From 2003 to 2009, she underwent 4 laparoscopies for the treatment of pain associated with endometriosis (dysmenorrhea, dyschezia). The first surgery, which was performed in 2003, revealed endometriosis grade IV. A gonadotropin-releasing hormone (GnRH) analogue (goserelin) was administered to her for 6 months after surgery, but the pain recurred soon after her menses returned. As the pelvic pain persisted, a new laparoscopy was performed in 2006, and the levonorgestrel intrauterine system (LNG-IUS, Mirena, Bayer, Leverkusen, Germany) was inserted, with partial pain relief. In 2008, she started complaining of dyschezia, and underwent a third laparoscopy, for which no records are available. In spite of using Mirena, the pain, as well as the dyschezia, persisted. Thus, she underwent a fourth surgery in 2009. Finally, a colonoscopy performed in 2010 revealed rectosigmoid stenosis probably due to extrinsic compression. She was advised to get pregnant before attempting to treat the intestinal lesion, in view of the risks involved in such a surgery.

Spontaneous pregnancy occurred soon after the LNG-IUS was removed in 2011. When the patient was in the 33rd week of pregnancy, she started feeling severe abdominal pain. No fever or sings of pelviperitonitis were present, but as the pain worsened, a cesarean section was performed, with the delivery of a premature healthy male. Unfortunately, an intestinal rupture was also identified. Severe peritoneal infection and sepsis ensued. A colostomy was performed, and the patient recovered after 8 days in intensive care. Three months later, the colostomy was closed, and a new Mirena was inserted. Only then did the patient come for treatment of the intestinal endometriosis with our multidisciplinary endometriosis team. The diagnostic evaluation, including a transvaginal ultrasound (TVUS) with intestinal preparation and a magnetic resonance imaging (MRI) scan ( - Fig. 1), revealed the presence of intestinal lesions, while the colonoscopy confirmed stenosis due to extrinsic compression of the rectum (-Fig. 2).

The patient then underwent a laparoscopic excision of the endometriotic lesions, including an ovarian endometrioma, adhesiolysis and segmental colectomy on November 2014. She is now fully recovered and planning a new pregnancy. A TVUS performed six months after surgery showed signs of pelvic adhesions, but no endometriotic lesions. 


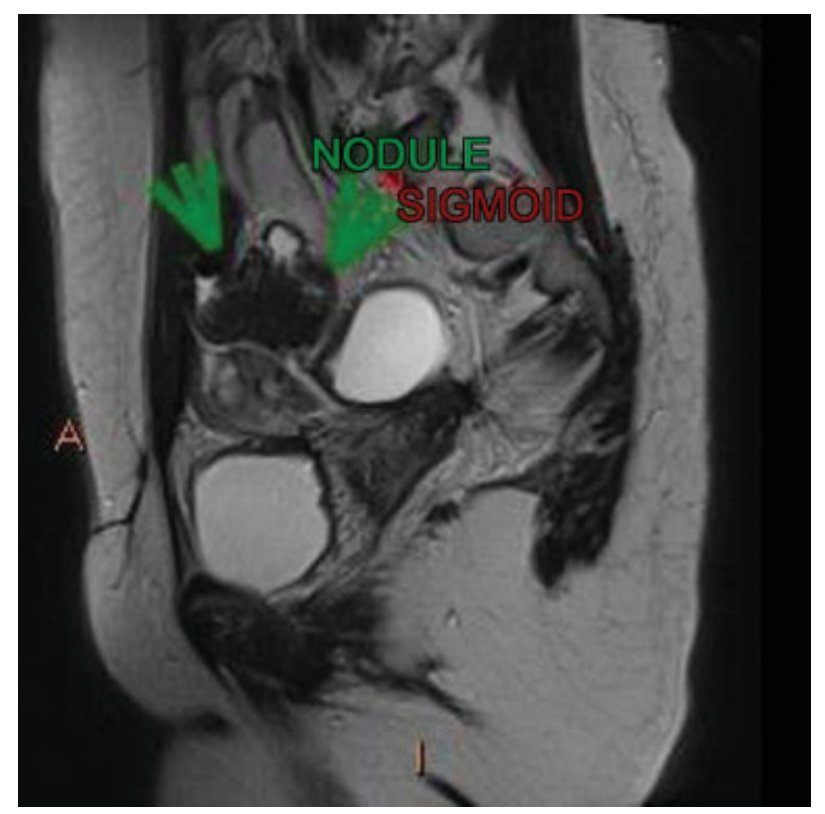

Fig. 1 Magnetic resonance imaging scan showing an endometriotic nodule in the rectosigmoid.

\section{Discussion}

Intestinal evaluation is extremely important for the surgical planning, since the number of lesions and the depth of invasion influence the composition of the surgical team, the equipment used and the technique chosen. Bowel involvement is frequently multifocal, and the most commonly affected areas are the rectosigmoid colon, the appendix, the cecum and the distal ileum. ${ }^{1,5}$ Although the rectal endoscopic sonographic approach is the most precise approach for the evaluation of the involvement of intestinal layers, such identification is also possible by TVUS. $^{4,5}$ It has been shown that lesions that affect more than $40 \%$ of the bowel circumference reach beyond the inner muscular layer. ${ }^{3-5}$

Women presenting with intestinal symptoms and those with previous endometriosis surgery are at increased risk of bowel resection. ${ }^{4,5}$ Our patient presented with recurrent symptoms, including dyschezia, despite four laparoscopies and the continuous use of medical treatments. The decision to perform surgery for DIE is mainly clinical. ${ }^{4,5}$ The TVUS and other imaging techniques such as the MRI can be useful tools to make a preoperative estimate of the size and lateral extension of the lesions, and they play a vital role in the surgical planning and approach. It remains unclear, however, to what extent the preoperative ultrasonography or the MRI should influence the decision to perform the surgery, or the decision regarding the type of intervention to undertake for DIE. ${ }^{5,6}$ According to the European Society of Human Reproduction and Embryology (ESHRE) Guideline, ${ }^{2}$ the ureter, the bladder and the bowels should be assessed if DIE is suspected, in order to establish the extent of the disease. Even though the colonoscopy performed in 2010 revealed rectosigmoid stenosis probably due to extrinsic compression, the patient was advised to get pregnant before attempting to treat the intestinal lesion, in view of the risks involved in such a surgery. As the patient only came to our multidisciplinary team after intestinal rupture in 2013, we do not know why she was not operated earlier, even though the decision to perform surgery may vary according to the literature.

Although the accuracy of the colonoscopy for the identification of intestinal involvement in DIE is debatable ${ }^{7}$ in view of the rarity of mucosal involvement, it was indicated in our patient due to the persistent intestinal symptoms. Indeed, the colonoscopy showed stenosis due to extrinsic compression. Therefore, surgery should have been contemplated before pregnancy, even though there is no consensus in the medical literature as to what is the best approach in such clinical settings. ${ }^{3,6}$ Once again, she was not previously under our care, and no record of clinical decisions was available to us.

Surgery is considered the treatment of choice for symptomatic DIE, as the complete removal of lesions results in significant pain relief and improvement in quality of life scores. $^{2,4,5}$ The best therapeutic approach for women with DIE involving the sigmoid and/or rectum remains to be established. ${ }^{4,5} \mathrm{~A}$ variety of factors such as clinical symptoms, lesion location and results from imaging studies (TVUS and MRI), as well as the recurrence rates and impact on fertility and quality of life should be taken into consideration., Some advocate that a bowel resection is rarely justified,
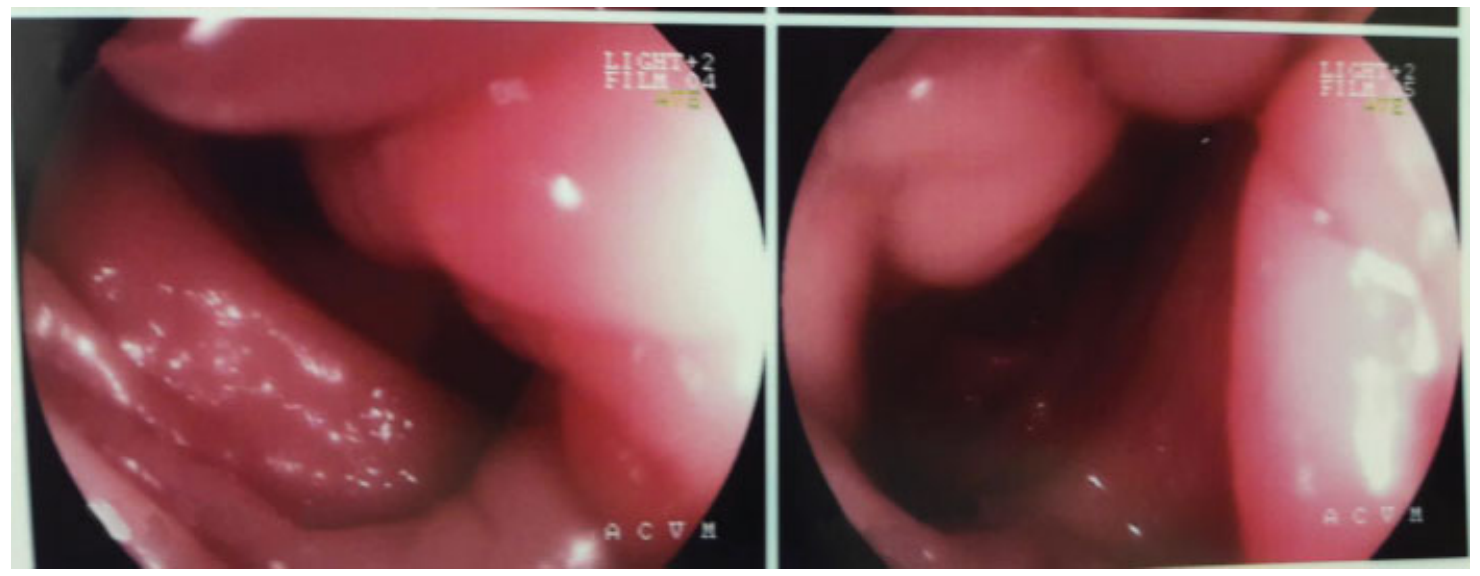

Fig. 2 Colonoscopy performed before surgery in 2014 showing extrinsic compression in the rectum by an endometriotic nodule. 
and that in many cases involving the rectovaginal septum or the bowel, DIE can be appropriately managed without the surgical excision of such lesions. ${ }^{8}$ A conservative approach seems justified in younger patients wishing to conceive, although segmental bowel resection and anastomosis result in better outcomes, without interfering in pregnancy rates. ${ }^{5}$ This may have been the case when our patient was first operated, as she was not infertile. Her clinical history, however, showed intestinal symptoms (dyschezia), and the medical treatment she underwent apparently was not enough to stop the progression of her intestinal endometriosis. In addition, the colonoscopy had already showed stenosis probably related to extrinsic compression. Unfortunately, none of the previous surgeries were performed by a multidisciplinary endometriosis team. It is advisable to refer women with DIE to a center of expertise in endometriosis that can offer multidisciplinary management, as the surgery is associated with significant complication rates. ${ }^{2}$

Disastrously, intestinal rupture during pregnancy occurred. Although rare, intestinal obstruction due to endometriosis during pregnancy may happen, with rather severe complications. Unfortunately, DIE might be overlooked, as symptoms can be elusive and unspecific, and intestinal lesions may be missed even during laparoscopy. Furthermore, smaller deep lesions, especially at the level of the sigmoid, may be missed during the diagnostic workup and laparoscopy. Last, but not least, one expects endometriosis to regress during pregnancy. ${ }^{2,9}$ Regrettably, there may be more cases, as many may not have been published. We have received personal communication of two other cases of intestinal rupture after controlled ovarian stimulation for in vitro fertilization (IVF). As a matter of fact, acute complications of endometriosis occurring during pregnancy remain rare. Setúbal et $\mathrm{al}^{9}$ published a review on intestinal complications caused by DIE either during pregnancy or IVF. Their literature search revealed 12 articles describing 12 complications related to the progression of DIE during pregnancy, and 1 article reporting 6 cases of bowel occlusion during IVF. Surgery is not mandatory in all cases, and when infertility is involved, IVF appears to be the best option. ${ }^{2}$

Women presenting with intestinal symptoms and those with previous endometriosis surgery are at increased risk of bowel resection. The decision to perform surgery in this setting, however, remains mainly clinical. Available published data on the long-term outcomes reveals a cumulative probability of pain recurrence between $20 \%$ and $40 \%$, and need of another surgical procedure between $15 \%$ and $20 \%$. Therefore, the decision to perform radical or conservative surgery or no surgical intervention at all should be evaluated individually. ${ }^{10}$ Accurate information on the benefits and risks involved in the procedure versus treatment without bowel resection should be available to all patients. The management of women with bowel endometriosis remains a challenge due to the lack of published studies evaluating the real risk of symptom recurrence, the effects on fertility, and the need for further surgical interventions. Decisions, however, should be individualized to the needs of each woman after providing information on the potential benefits, harms, and costs of each treatment alternative, as well as after evaluating the presence of pelvic pain, the woman's age, lesion location, and previous treatments. ${ }^{10}$ In such a setting, the evaluation by a multidisciplinary endometriosis team is a fundamental step in order to achieve successful results.

\section{Conflicts to Interest}

The authors have no conflicts of interest to disclose.

\section{Acknowledgments}

The authors wish to acknowledge that the surgeon responsible for the case herein reported was Dr. Ivone Dirk de Souza Filogonio. Unfortunately, she passed away in December 2015. For over 30 years, Dr. Filogonio was responsible for hundreds of surgeries, and in the past 20 years, she devoted most of her time to the development of our multidisciplinary endometriosis team.

\section{References}

1 Koninckx PR, Ussia A, Adamyan L, Wattiez A, Donnez J. Deep endometriosis: definition, diagnosis, and treatment. Fertil Steril 2012;98(03):564-571. Doi: 10.1016/j.fertnstert.2012.07.1061

2 Dunselman GA, Vermeulen N, Becker C, et al; European Society of Human Reproduction and Embryology. ESHRE guideline: management of women with endometriosis. Hum Reprod 2014;29 (03):400-412. Doi: 10.1093/humrep/det457

3 De Cicco C, Corona R, Schonman R, Mailova K, Ussia A, Koninckx P. Bowel resection for deep endometriosis: a systematic review. BJOG 2011;118(03):285-291. Doi: 10.1111/j.1471-0528.2010.02744.X

4 Meuleman C, Tomassetti C, D'Hoore A, et al. Surgical treatment of deeply infiltrating endometriosis with colorectal involvement. Hum Reprod Update 2011;17(03):311-326. Doi: 10.1093/humupd/ dmq057

5 Abrão MS, Petraglia F, Falcone T, Keckstein J, Osuga Y, Chapron C. Deep endometriosis infiltrating the recto-sigmoid: critical factors to consider before management. Hum Reprod Update 2015;21 (03):329-339. Doi: 10.1093/humupd/dmv003

6 Carneiro MM, Filogônio ID, Costa LM, de Ávila I, Ferreira MC. Clinical prediction of deeply infiltrating endometriosis before surgery: is it feasible? A review of the literature. BioMed Res Int 2013;2013:564153

7 Milone M, Mollo A, Musella M, et al. Role of colonoscopy in the diagnostic work-up of bowel endometriosis. World J Gastroenterol 2015;21(16):4997-5001. Doi: 10.3748/wjg.v21. i16.4997

8 Acién P, Núñez C, Quereda F, Velasco I, Valiente M, Vidal V. Is a bowel resection necessary for deep endometriosis with rectovaginal or colorectal involvement? Int J Womens Health 2013; 5:449-455. Doi: 10.2147/IJWH.S46519

9 Setúbal A, Sidiropoulou Z, Torgal M, Casal E, Lourenço C, Koninckx P. Bowel complications of deep endometriosis during pregnancy or in vitro fertilization. Fertil Steril 2014;101(02):442-446. Doi: 10.1016/j.fertnstert.2013.11.001

10 Carneiro MM, Costa LMP, Ávila I. To operate or not to operate on women with deep infiltrating endometriosis (DIE) before in vitro fertilization (IVF). JBRA Assist Reprod 2017;21(02):120-125. Doi: 10.5935/1518-0557.20170027 